\title{
A LIDERANÇA CARISMÁTICA DE STEVE JOBS
}

Rodrigo César Tavares Cavalcanti - rodrigoc.pesquisa@gmail.com ${ }^{1}$

Resumo - Líderes exercem fascínio sobre seus liderados e, muitas vezes, são tidos como detentores de poderes mágicos. Steve Jobs - empreendedor da área de tecnologia - foi um dos líderes mais alardeados pela mídia e, ao mesmo tempo em que seduz os crédulos, levanta questionamentos da comunidade científica. O problema foi discutido sob a ótica da teoria da dominação de Max Weber, mais especificamente por meio do conceito de liderança carismática. Uma pesquisa documental gerou dados que revelam depoimentos de ex-funcionários de Jobs e informações sobre sua carreira que ajudam a entender o fenômeno. O artigo, então, conclui que a trajetória de Steve Jobs tem características muito próximas do entendimento de uma dominação carismática.

Palavras-chave: Steve Jobs, Max Weber, liderança carismática.

\section{STEVE JOBS CHARISMATIC LEADERSHIP}

\begin{abstract}
Leaders fascinate their followers and are often seen as empowered magicians. For example, Steve Jobs - a technology entrepreneur - was one of the most talked about leaders in the media and, while seducing the credulous, him raised questions to the scientific community. In tihis text, this problem was discussed from the perspective of Max Weber's theory of domination, more specifically through the concept of leadership charismatic. A documentary search generated data that revealed testimonials from former Jobs employees and career information that helped to understand the phenomenon. The article then concludes that the trajectory of Steve Jobs has characteristics very close to the understanding of a charismatic domination.
\end{abstract}

Keywords: Steve Jobs, Max Weber, charismatic leadership. 


\section{Introdução}

Na construção da história, os líderes têm um papel de destaque (GIFFORD, 20II). Júlio César, Napoleão Bonaparte, Benjamin Franklin, Winston Churchill, Martin Luther King, esses personagens sempre exerceram grande fascínio não só sobre aqueles que os seguiram, mas naqueles que observaram e estudaram seus feitos.

Um dos líderes mais comentados da história recente é Steve Jobs. Seu destaque nesse papel vem da sua capacidade de guiar profissionais da área de tecnologia e gestão mesmo sem ter concluído seus estudos na universidade. Ele explicava sua capacidade com uma metáfora segundo a qual ele não era um grande músico, mas entendia bem o suficiente da sinfonia para reger a orquestra. O resultado disso está em nossas mãos: computadores, smartphones, tablets e toda uma onda de inovações tecnológicas que dominam nosso dia a dia (ISAACSON, 20II).

A questão é o que está por trás de uma explicação que parece ser tão simples quanto essa da metáfora da orquestra. Mesmo em uma orquestra real, sabe-se que o maestro precisa de anos de estudo e dedicação para adquirir as habilidades necessárias para reger uma grande quantidade de músicos. Nesse sentido, o cientista vai além da metáfora quando pergunta: o que fez Steve Jobs para guiar profissionais e obter resultados tão expressivos? Portanto, pode-se dizer que o objetivo do trabalho foi entender e caracterizar que tipo de liderança deu força a Steve Jobs na sua carreira como empreendedor.

Um dos pontos a se considerar é o início de sua carreira na fundação da Apple e a sua amizade com o engenheiro Steve Wozniak. Sua visão do que Wozniak poderia construir com seus conhecimentos foi um dos propulsores do desenvolvimento de seus produtos. Essa visão inovadora de Jobs se mostra como uma máquina de encantamento capaz de orientar profissionais e criar uma original cultura de qualidade nos seus empreendimentos (ISAACSON, 20II).

O que parece ser um superpoder de enxergar além, que encanta aqueles que estão ao seu redor, se assemelha com o que Weber (1994) tratava como a capacidade especial do líder carismático. Para ele, uma das formas de os liderados enxergarem o carisma de alguém é como uma habilidade mágica. Esse é um indício que leva a questionar a trajetória desse empreendedor.

A principal justificativa para este estudo é a desmistificação de um dos mitos relacionados a Steve Jobs. Muitas vezes a mídia não está comprometida com uma observação científica dos fatos, pelo contrário, ela acaba exaltando e criando fantasias perigosas para o entendimento de personalidades públicas. Nesse sentido, entender sua liderança como algo passível de explicação racional presta um serviço de esclarecimento à sociedade.

Também pode-se mencionar como justificativa a contribuição de um estudo focado na liderança de Steve Jobs, já que existem poucos artigos com essa proposta (SHARMA, 20II). Além disso, este artigo também expande as explicações acerca de um dos maiores empreendedores da área de tecnologia. Conhecido pelos seus feitos de hardware e software, pouco ainda se sabe sobre a seara social que permeia a história desse idealizador de computadores. 


\section{A visão de Max Weber de liderança carismática}

A ideia da liderança carismática foi desenvolvida por Weber (1994). Ele trata do líder carismático como aquele que exerce dominação por algo que dele emana em vez de seu cargo ou de um histórico que o favoreça. Weber descreve o líder carismático como alguém com poderes ditos como sobrenaturais. Na verdade, ele aparece dentro da trama de poder como alguém fora do comum, ao ponto de ser considerado alguém com capacidades divinas.

A caracterização do líder carismático exige um olhar ainda mais acurado. Ele é aquele visto como detentor de uma capacidade superior associada a uma missão. Se, porventura, alguém com habilidades notórias surge em determinado meio social, é possível que obtenha reconhecimento e adquira certo prestígio. No entanto, isso não é suficiente para que as pessoas ao seu redor se tornem seus seguidores. A missão do líder carismático é que vai dar um sentido para que os outros o sigam, acreditando no seu poder e no caminho que esse líder aponta para os demais. A teoria ainda sinaliza que o portador de carisma assume tarefas relacionadas a sua missão e é através dela que obtém obediência. A missão é, então, um dos pontos importantes na caracterização da liderança carismática (WEBER, I994).

Weber (1994) aponta que esse líder nega a busca racional por ganhos econômicos em sua atividade. Se um herói de guerra conquista um território e, com isso, alcança uma boa posição econômica, seu carisma não viria da sua sede por recompensas desse tipo, mas da sua vontade de dar uma vitória ao seu povo. Essa liderança se caracteriza por algo que destoa das buscas cotidianas, tido como algo maior, algo revolucionário.

Weber (1994) aponta que o carismático terá de provar suas excepcionais capacidades e essas provas mostrarão que ele é capaz de grandes feitos em sua missão, o que trará o apoio daqueles que o observam. Isso prova que o carisma não é algo mágico que encanta os seguidores de forma mágica, sem um fundamento objetivo.

Um outro elemento que caracteriza o indivíduo carismático é sua capacidade de subverter a ordem vigente. O líder carismático age de maneira revolucionária, invertendo valores e desestabilizando estruturas burocráticas e tradicionais (WEBER, I994). Não basta a dominação, ele precisa apresentar grandes poderes que servem para desestabilizar ordens inadequadas; a missão só importa se tiver em seu fluxo a novidade, uma nova maneira de organizar o que já existe.

Weber (1994) deixa claro que o poder do líder carismático age de dentro para fora, no nível das crenças dos subordinados, transformando aquilo em que acreditam, gerando submissão. Dessa forma, os poderes especiais não encantam só por encantar, eles estão associados a esse poder de persuasão que incide internamente; a missão também não é revolucionária à toa, ela vem para ficar no lugar do que já existe e criar caminhos para a dominação.

Apesar de estar presente na interação do líder carismático com seus seguidores e chegar a circunstâncias nas quais alguns podem ver feitos divinos, o carisma pode vir a desaparecer. Circunstâncias como a morte do portador do carisma podem gerar o fim da dominação e levar 
os liderados a uma situação não desejável por aqueles que dominam. Situações como essa são previstas e apontam para novas formas de manter o poder sobre os dominados; existe então uma mudança de situação para contextos burocráticos e tradicionais. $\mathrm{O}$ carisma passa a ser utilizado para dar credibilidade a novas práticas institucionais apoiadas pelo ainda portador do carisma, como, por exemplo, a associação da posição carismática com laços de sangue ou de dons semelhantes (WEBER, 1994).

\section{Atualizações do entendimento weberiano de carisma}

Outros autores atualizaram o pensamento de Weber e é deles que este artigo trata a partir de agora. Klen e House (1995) e Bowden (2010) defendem que existem três elementos importantes no processo carismático: (I) o líder com qualidades especiais, (2) uma relação especial entre esse líder e um grupo em estado propício à dominação e (3) um contexto mais amplo que permite a mudança que a liderança carismática prega. Klen e House (I995) utilizam uma metáfora na qual o carisma é a chama, o líder carismático é a fagulha, os possíveis seguidores são o material inflamável e o contexto propício à dominação é o oxigênio.

Desse modo é possível enxergar que é a interação entre esses elementos que permite o acontecimento da dominação carismática. Nesse sentido, tal entendimento ajuda a não cair no erro de considerar o portador do carisma como um ser capaz de liderar qualquer tipo de indivíduo em qualquer tipo de contexto. Uma atenção especial deve ser dada à interação entre os envolvidos e não só ao poder de encantamento do líder carismático.

Jermier (1993) apresenta uma maneira diferente de pensar a forma como o líder carismático se projeta diante dos seus seguidores. Foi dito que o portador de carisma traz consigo uma sede de mudança brusca e seu triunfo estaria relacionado a uma missão revolucionária. Jermier argumenta que nem sempre o líder carismático alcança seus seguidores através dessa mudança social brusca. Ele admite que o relacionamento entre esse líder e seus seguidores é diverso e pode se apoiar em mensagens não revolucionárias, em filosofias do dia a dia e em outras maneiras de inspirar transformação e transcendência. Ele ainda afirma que elementos como as qualidades do líder, as características dos seguidores e fatores situacionais podem intervir decisivamente na dominação.

Já Roselino (20I0) fala da influência do líder em seu movimento de dominação, que parte de dentro para fora. Ele argumenta que se trata de uma dinâmica diferente daquela que parte do que é externo, isto é, da influência das transformações político-econômicas que estão ao redor dos dominados. Ele defende que o carisma atua interiormente, mas sem cair em um fatalismo ou em uma visão idealista: é algo externo, na verdade, a um processo de racionalização. O carisma atuaria, então, em uma dimensão intuitiva do aprendizado e seria um processo bem mais sutil do que a força instrumental da racionalidade envolvida em processos burocráticos.

Ainda sobre isso, Ramos (2006) pontua que essa transformação sutil pode ser vista no modo com que os indivíduos operam os problemas e circunstâncias da vida, nas suas mudanças de atitudes diante do mundo. O líder carismático atuaria renovando a intelectualidade nascida a partir da indulgência ou do entusiasmo e reformaria a própria maneira com que o os dominados 
se orientam diante do mundo. Dessa maneira, o carisma funcionaria de maneira adversa a uma imposição, como as obrigações das leis ou o peso histórico do carisma; ele seria, por outro lado, uma sugestão que brotaria de dentro do dominado e o faria ver o mundo ao gosto do líder carismático e da sua missão.

Esse encantamento carismático que faz com que o subordinado se transforme foi estudado por Ladkin (2006). Ele defende que a experiência do fenômeno carismático desperta nos seguidores o que ele define como o conceito do sublime. Ladkin entende o sublime como algo aterrorizante, mas que traz energia e vigor. Aqueles que experimentam o sublime se conectam com um plano de realidade diferente, algo além do comum, como em um encontro com uma pirâmide do Egito ou outro monumento grandioso. Essa sensação incluiria ainda a sensação da existência da morte, o descobrimento da vida pulsando em si e a consequente necessidade de continuar lutando para viver. Ladkin faz o paralelo dessa experiência incomum com o que Weber (1994) chama de mágica que envolve o carisma, a sensação de caos e a posterior constatação da nova ordem proposta pelo líder. Essa seria uma interpretação do encantamento proveniente dos poderes sobrenaturais do líder carismático, algo capaz de mudar as convicções dos indivíduos e os fazerem mudar em nome de uma missão.

Enquanto Ladkin discute o líder carismático como aquele capaz de proporcionar o sublime, Santos (20I4) trata desse líder como alguém capaz de renovar valores e combater a burocratização da vida. Ele mostra o portador de carisma como alguém além-do-homem nietzschiano. Seria alguém capaz de enfrentar a decadência de valores implantados pela burocracia ou pela tradição e sugerir algo novo para colocar nesse lugar. O carisma seria o símbolo de uma nova postura ética, antagônica à ordem vigente e contestadora da racionalização, perda de sentido e fragmentação. Esse entendimento ratifica a noção do líder carismático como revolucionário, no entanto, com se viu, ele não se limita à revolução e, nesse caso, a concepção do além-do-homem pode se tornar limitadora. Mas, no que diz respeito ao caráter de mudança que o carisma evoca, a visão de Santos permite visualizar com mais riqueza quem seria esse líder no contexto dos valores e da racionalidade.

Ditomaso (1993) indica que o líder carismático é revolucionário, no entanto, questiona se ele é sempre considerado alguém importante, se pode ser malvisto dentro da organização. Essa defende que as organizações possuem mecanismos de correção de prevenção de erros e remoção de ameaças. Nesse sentido, o portador de carisma, sendo renovador, pode incomodar e ser considerado danoso ao ambiente organizacional. Muitas vezes o processo carismático é visto como algo triunfante e vitorioso e não se consideram as dificuldades que o líder enfrenta na sua missão. É possível entender através dessa consideração as possíveis resistências às reformas do portador do carisma e enriquecer ainda mais a análise.

Pensando além do líder carismático, pode-se pensar na relação entre ele e seus seguidores. Klein e House (1995) defendem que não é de todo razoável dizer que existe algum elemento especial em líderes carismáticos quando a interação entre esse líder e os subordinados diz muito mais do que ele isoladamente. 
Em consonância com tal preocupação, foram levantadas três questões que podem revelar mais sobre a disposição de certos indivíduos para seguirem líderes carismáticos. A primeira delas afirma que potenciais seguidores estão em busca de um significado para suas vidas (KLEIN; HOUSE, I995). Assim, o líder carismático seria aquele que daria um sentido àqueles que se veem esvaziados dele.

Uma outra possível condição para indivíduos se tornarem seguidores seria a compatibilidade entre líder e liderado. O portador de carisma pode comunicar uma visão e um estilo que são valorizados pelos seguidores, o que tornaria essas qualidades persuasivas e guiariam a influência desse líder diante dos indivíduos (KLEIN; HOUSE, I995).

A terceira possibilidade estaria relacionada à moral. Os dominados seriam mais facilmente liderados por um líder carismático que atendesse a uma demanda por determinado aspecto moral dos indivíduos (KLEIN; HOUSE, I995). Deveria haver nos liderados, assim, uma sede não só por sentido ou identificação, mas uma resposta moral para a missão a que se refere o líder carismático.

Yuki (I999) também discute a relação entre líder carismático e seus liderados. Ele defende que o carisma atua nos indivíduos a partir do entendimento de um líder que identifica soluções para importantes problemas que eles enfrentam. Os liderados, nessa condição, agem para conseguir a aceitação e aprovação do líder, chegando a fazer sacrifícios, mostrar iniciativa e obediência, tudo para ser aceito pelo líder. Esses liderados evitam refletir sobre a liderança mesmo que suas obrigações sejam impraticáveis e irreais.

Sobre o ambiente propício para o surgimento da liderança carismática, Klein e House (I995) defendem que um contexto de crise aumenta as chances desse tipo de dominação surgir. Eles argumentam que a crise deixa os indivíduos estressados e com alto nível de incerteza, o que favorece uma liderança que oferece uma esperançosa possibilidade de resolver essa situação, através de uma visão inspiradora.

Apesar da relevância da crise para a liderança carismática, Beyer (I999) alerta que essa não é uma condição essencial para que o carisma se desenvolva. Outro ponto mencionado por ele sinaliza que os estudos sobre carisma podem identificar as crises em diferentes contextos. A importância dela aparece mais nos casos de manutenção do carisma do que em sua aparição.

Outra condição contextual que dá possibilidade de a liderança carismática se colocar é a cultura. House (I999) reforça esse ponto de vista ao constatar que diferentes contextos permitem também diferentes líderes carismáticos e que esses líderes são compreendidos ou não em suas ações de acordo com uma certa compatibilidade cultural.

Bowden (20I0) ratifica que esse tipo de liderança emerge de um contexto cultural compatível. Ao analisar o papel carismático de Barack Obama, ele conclui que a retórica do ex-presidente americano gira em torno de elementos culturais valorizados pelos eleitores dos Estados Unidos. Ele afirma que Obama apela para uma ideia de comunidade norte-americana, uma 
concepção de união confirmada pelo fato de ele ser filho de um pai negro e uma mãe branca. É esse apelo a narrativas dispersas na cultura desse país que favorece a ascensão do presidente como líder carismático.

Uma conclusão semelhante é feita por Filho e Costa (2006) ao estudar o caso de Lula. Eles afirmam que o ex-presidente constrói um discurso repleto de valores de igualdade social que está presente na sociedade devido à histórica influência cristã e seus valores de caridade. O líder carismático envolve os liderados a partir de crenças que já existem e podem ser reorganizadas de tal forma a favorecer a construção de uma missão que inspire os que estão a sua volta. É essa permissão cultural que caracteriza, nesse caso, o contexto como favorável a uma influência carismática.

Já Bryman (I993) afirma que, mesmo com uma liderança carismática plena, existem dissidências, indivíduos que desobedecem e contestam essa liderança. A perda de carisma, segundo ele, se dá quando alguns não acreditam nas evidências de seus poderes ou não são convencidos pela retórica do portador de carisma.

Por sua vez, Conger (1993) ressalta que esse carisma pode se extinguir e dar forma a uma nova ordem social, regras, tradições e instituições podem se tornar estabilizadoras dessa nova ordem. O carisma é então rotinizado e burocratizado, e corre o risco de desaparecer se suas visões e valores não forem mantidos. Esse carisma pode passar por um processo em que passa a ser impessoal e residir em uma instituição em vez de um líder. Diferente de uma burocratização gradual, o carisma se mantém de alguma forma e passa a ser localizado na instituição, constituindo possivelmente organizações carismáticas (BREIUILLY, 20II). Calás (I993) ainda aponta para uma outra alternativa de quando o carisma se esgota. A rotinização dele pode não culminar com uma burocratização nem com a organização carismática, mas com uma comunidade na qual permanecem os valores disseminados pela visão do então portador do carisma.

\section{Procedimentos metodológicos}

Para responder se Steve Jobs pode ou não ser entendido como líder carismático, recorreu-se, em nível de dados, a documentos da internet, o que caracteriza esta pesquisa como documental. Trata-se ainda de uma pesquisa qualitativa por não partir de um modelo teórico $a$ priori, não procurar fazer mensurações e nem se debruçar em amostragens aleatórias (FLICK, 2004), mas em dados qualitativos específicos que revelem informações úteis sobre um determinado caso.

O objeto de estudo adotado foi a trajetória de Steve como líder Jobs devido à relevância de tal histórico, evidenciado pela notória e exaustiva divulgação nos meios de comunicação. Em busca de uma resposta pelo poder emanado de tal figura, dentre as descritas por Weber (1994), chama a atenção a carismática pelo forte apelo ao indivíduo destacado nos dados, bem mais que poderes burocráticos ou tribais. Os indícios apontavam para o poder carismático e restava encontrar embasamento por meio de relações pertinentes e profundas para caracterizar a liderança como tal. Uma vez embasado, pode-se partir para a caracterização do fenômeno. 
Os documentos, dados secundários, foram compostos de reportagens e entrevistas sobre o empreendedor. Foram 32 peças jornalísticas no total, sendo 30 delas feitas por sites estrangeiros, em inglês, e apenas duas brasileiras, em português. Construiu-se então um corpus conforme orienta Bauer e Aarts (20I0). Um primeiro cuidado foi dar homogeneidade ao grupo de documentos, o que se conseguiu ao coletar apenas as matérias jornalísticas que, em seu conteúdo, respondiam à seguinte questão: este documento contém dados sobre a maneira com que Steve Jobs liderava seus seguidores? Caso sim, o arquivo era coletado; em caso negativo, a página era arquivada em um subconjunto de dados à parte. Foi necessário estipular esse parâmetro também pela grande quantidade de informação disponível na web. Com termos de busca que remetiam ao empreendedor e sua maneira de lidar com subordinados, diversas páginas apareciam e nem sempre traziam apontamentos interessantes para a pesquisa, muitos se repetiam ou não traziam detalhes suficientes para se ter como dado. Apesar da grande quantidade de tempo utilizada, foi possível chegar a um conteúdo útil que acelerou o processo de análise posteriormente.

Um outro cuidado citado por Bauer e Aarts (20I0) é o foco temático. Sendo assim, todo o material coletado diz respeito somente a Steve Jobs e ao tipo de dominação relacionada a sua atuação na Apple. Isso quer dizer que, por exemplo, materiais como os que apenas divulgavam com tons promocionais foram descartados. Um outro ponto citado como eficaz para a construção do corpus foi a saturação. Mesmo com a vasta quantidade de material disponível na internet, uma certa repetição se mostrou depois da aplicação dos filtros já mencionados. Assim que os dados deram sinais de já não poder revelar algo novo, foi dada por encerrada a coleta. Todas as peças jornalísticas foram salvas em formato de texto e armazenadas em local que tornasse o acesso viável.

O modo de análise empregado foi o da análise qualitativa conforme proposta por Creswell (20I0), composta de inferências sistematizadas com base na teoria e nos dados que, no caso deste artigo, são fruto das informações descritas pela mídia, incluindo citações diretas utilizadas nas matérias. Tendo feito uma leitura inicial de todo o material coletado, pode-se partir para a literatura com algumas categorias preliminares baseadas no conceito de liderança carismática. Em leituras posteriores, foi-se codificando o conteúdo analisado conforme categorias baseadas no conceito analisado. Esse procedimento permitiu que a liderança carismática fosse identificada com mais clareza no fenômeno estudado. Tendo as relações postas, foi possível observar os dados com mais profundidade de acordo com os conceitos weberianos e construir as conclusões pertinentes. A etapa seguinte foi a de organizar o conteúdo e as relações encontradas em uma narrativa inteligível para uma leitura mais intuitiva tendo como estrutura o próprio ciclo do fenômeno do carisma e da trajetória de Steve Jobs.

\section{Steve Jobs como líder carismático}

A trajetória de uma liderança carismática tem como ponto de referência uma grande excitação, uma situação de grande resolução em momento propício ou um acontecimento que faça com que os possíveis liderados se curvem diante do poder e das evidências do portador de carisma. Condição essa mostrada no referencial como a evidência de excepcionais capacidades do líder (WEBER, 1994), do encantamento carismático (LADKIN, 2006) e de um contexto propício para atuação desse tipo de líder (KLEN; HOUSE, I995; BOWDEN, 20Io). Steve Jobs 
teve esse momento na década de 80, época em que a Apple iniciava sua trajetória ao construir o primeiro computador pessoal da história. A partir de agora, mostramos esse primeiro aspecto da liderança carismática de Steve Jobs: o momento excitante de um grande feito que atesta as capacidades excepcionais do líder.

Jobs trouxe a proposta de construir um computador para o seu engenheiro e amigo Steve Wozniak, que, por sua vez, havia chamado Bill Fernandez, colega de trabalho na HP, para ajudar no sistema elétrico da máquina. As ideias de Jobs eram implementadas pelos outros dois, que assistiam fascinados ao nascimento da empresa e daquele tipo de produção. Isso causou uma excitação, narrada por Bill Fernandez:

It was just me. And for a long time it was just Jobs and me because Woz was still working at HP. Jobs and I were in the garage. Woz was in between HP and his apartment... It was incredible. I'd be sitting in the garage and Woz would come in and say, 'You gotta see this program.' ... Things were always happening and always growing and always moving forward. There was always forward motion.

Bill, em entrevista, ainda dá outra declaração sobre o furor que gerava a construção das máquinas idealizadas por Steve Jobs:

\footnotetext{
There was magic in the air. There was a palpable sense that magic was in the air. There was also this implication that we were going to change the world, or we were going to change society in a significant way... [There was] the sense that anything was possible, that we were fulfilling the growing demand and desire for people to own their own computers, that we were empowering ordinary people to do things unimaginable, that we were putting the latent, potential power of technology into the hands of the people.
}

A qualidade, a vanguarda e o sucesso da maioria dos produtos da Apple atestam a capacidade do CEO ao longo de sua história e são as evidências do poder excepcional da liderança carismática, conforme será exibido a partir de agora. Esse entendimento foi apontado no referencial teórico como as noções de poder ditas como sobrenaturais e capacidades excepcionais (WEBER, I994; KLEN; HOUSE, I995; BOWDEN, 20I0), assim como a habilidade de trazer soluções para os problemas que enfrentam (YUKI, I999).

Em sua época, fim da década de 90, o Imac foi o computador pessoal mais vendido nos Estados Unidos. A facilidade de instalação e usabilidade atraíram diversas pessoas que nunca haviam tido contato com tecnologia semelhante. O design é outro destaque que fazia com que o produto fosse diferente e bonito de uma maneira que nenhum outro na sua época havia sido. Esse produto foi fruto do aprimoramento da obsessão inicial de Jobs: fazer com que um computador com diversas funcionalidades computacionais e com visual atraente chegasse na casa de pessoas comuns e não só nos escritórios de grandes organizações.

Devido ao seu comportamento tido como arrogante e impetuoso, Steve foi demitido da empresa que fundou. Durante o período de afastamento, ele se envolveu com outras organizações. Uma delas foi a Pixar, a qual ele adquiriu do cineasta George Lucas. Jobs mudou os rumos da empresa e fez com que em I995 fosse lançado Toy Story, o filme que revolucionou o uso da 
computação no cinema e que fez com que os $80 \%$ das ações da empresa que pertenciam a Jobs valessem I bilhão. Um outro empreendimento de Steve foi a criação da também empresa de tecnologia NeXT. Apesar de não ter alcançado o mesmo êxito da Apple, foi nessa organização que desenvolveu um sistema que revolucionaria o mercado de computadores pessoais. A Apple comprou a $\mathrm{NeXT}$ e aproveitou esse sistema, que, em 200I, se tornaria Mac $O S X$, o qual tornaria possível o processamento e a interface ainda mais atraentes.

Também em 200I foi lançado, por iniciativa de Jobs, o iPod, um reprodutor de mp3 cuja usabilidade surpreendeu o público e serviu de referência para o futuro dos projetos na área. Além disso, o mercado da música ainda conheceu a plataforma iTunes, da Apple, que permitia o download pago de arquivos de música. Mais uma vez a interface e a funcionalidade se destacaram de todos os padrões que já existiam na indústria. Com ele era possível fazer downloads a 99 centavos de dólar, com a maior variedade de músicas já vista e ouvi-las através de outros produtos da Apple com uma dinâmica atraente e inovadora. Os produtos da empresa ficavam cada vez mais integrados na experiência do usuário.

A visão de Jobs ainda proporcionou o surgimento do iPhone, gerando mais uma mudança de paradigma. O padrão dos dispositivos de telefones móveis se tornou aquele ditado pelo lançamento da Apple. A comunicação móvel ganhava um conceito diferente do celular: agora o mercado conhecia os smartphones. A última evidência da visão de Steve Jobs encontrada nos dados foi o lançamento do $i P a d$. Mais uma nova lógica no mercado era introduzida com os dispositivos tão funcionais como um computador e tão móveis quanto um celular, conhecidos por tablets. Mas o iPad não costuma ser chamado como tablet apesar de introduzir esse conceito no mercado, assim mantendo sua diferenciação e originalidade (o mesmo aconteceu com o iPhone e o smartphone).

Como foi visto, Jobs estava envolvido em todos os lançamentos de novos produtos e não é à toa que seja atribuído a ele grande parte do mérito da criação desses produtos que mudaram paradigmas dentro da tecnologia e da vida contemporânea. Todos esses feitos contribuem para as evidências do poder do líder carismático. Cada projeto bem-sucedido em que ele se envolveu entra para sua história e a criação de uma narrativa de grandes feitos que só fortalece a força da missão que prega, assim contribuindo a para a construção de seu carisma.

Assim, faz-se a leitura de que os resultados alcançados por ele eram as evidências de seus poderes tidos como sobrenaturais pelos liderados. Os trechos a seguir mostram como era a leitura de seus liderados: não só seus feitos, mas suas ações na rotina da organização, que sinalizam para capacidades que impressionavam aqueles que estavam ao seu redor e possuíam forte relação com a missão que pregava.

Um ex-empregado chamado Frederick Van Johnson atribui a Jobs uma grande capacidade de ter insights produtivos: "Because he has that insight. You know, he's Steve. And you're like, how did [he] even know that? [He's] absolutely right. And it's not even blowing smoke. Normally, he has some sort of weird insight where he just knows". 
Já Lee Clow, também ex-funcionário, fala do seu trato em relação ao trabalho de marketing da Apple: "There's not a CEO on the planet who deals with marketing the way Steve does. Every Wednesday he approves each new commercial, print ad, and billboard".

Chuq Von Rospach, um ex-funcionário da Apple e então funcionário da HP, relata seu apreço por uma certa dimensão visionária que enxergava em Steve Jobs:

Try to imagine today's society if Steve didn't exist. Can you? The Apple II. the Macintosh. The mouse. Making computers accessible to non-technical people in general. Reinventing the music industry with iPod and iTunes, over the express wishes of the industry. Beginning a similar reinvention of film and video. Revitalising animation with Pixar. Reinventing the personal communication industry with the $i$ Phone. And most recently the iPad. He was a fundamental part of so many societal changes, any one of which would make most people's careers.

Ainda completa comentando sua admiração pela maneira como Jobs atuava na Apple:

Steve could be a tough and very intimidating person, but as much as he demanded of others, he demanded more of himself. He was involved in one of my projects at Apple, and I used to watch the team scramble as Steve reviewed ad copy hours before a launch and mark up changes. He was that involved in the details, and he was always right.

Um outro ex-funcionário, que não se identificou, fala do talento e da capacidade de Jobs de trabalhar na produção de novos produtos e da sua maneira de trabalhar:

Steve's Apple had the most talented people in the world, the subtle chaos necessary to develop new ideas, and the relentless requirement to always meet his highest of standards. Steve Jobs has been described as "brilliant" and "mean" in the same breath. Brilliant because of his insight and vision, mean because he would let you know if your ideas weren't insightful or visionary.

Tim Cook, que assumiu a presidência da empresa após a morte de Steve, comenta sobre sua capacidade de liderança: "Steve has been an incredible leader and mentor to me, as well as to the entire executive team and our amazing employees".

A visão de Steve Jobs sobre a importância do design (um dos pontos fortes dos produtos da Apple) é lembrada por Bill Fernandez:

First and foremost, Steve Jobs thought of himself as an artist, and he encouraged the design team to think of ourselves that way, too... Since the Macintosh team were artists, it was only appropriate that we sign our work. Steve came up with the awesome idea of having each team member's signature engraved on the hard tool that molded the plastic case, so our signatures would appear inside the case of every Mac that rolled off the production line.

Esses relatos podem não comprovar a atuação de Jobs em si, mas ajudam a entender a leitura que os liderados por ele tinham de sua atuação na empresa. Ele não era lembrado pela sua história ou cargo, mas por sua capacidade, o dito poder sobrenatural atribuído aos líderes carismáticos. 
Essas suas excepcionais habilidades estão intimamente ligadas com a sua missão como líder. Missão essa apontada como aquela que persuade com intensidade aqueles submetidos pela liderança carismática (WEBER, I994; JERMIER, 1993) e que reorienta os liderados diante circunstâncias da vida (RAMOS, 2006; SANTOS, 20I4). Jobs criou um discurso que colocava a Apple como uma empresa que entraria para a história, que mudaria a vida das pessoas, dentro e fora da empresa, através da excelência, rigor e maneira única e engenhosa de seus produtos interagirem com os que estavam ao seu redor.

Uma citação atribuída a ele revela seu foco em fazer produtos de maneira singular: We started out to get a computer in the hands of everyday people, and we succeeded beyond our wildest dreams". Sua visão de que a Apple foi criada para mudar o mundo está presente na frase de convite de trabalho a um grande executivo da Pepsi: "Do you want to spend the rest of your life selling sugared water to children, or do you want a chance to change the world?".

Seu compromisso com a qualidade dos produtos é uma das grandes evidências do apego a sua missão como líder carismático. Um aspecto visível desse apego era sua hostilidade ao lidar com os seus subordinados, como conta o ex-funcionário Guy Kawasaki': "Ele não hesitava em dizer para as pessoas, em frente de um departamento inteiro, o quão estúpidas e sem senso algum elas eram e eu morria de medo disso. Dito isso, eu não trocaria o meu trabalho para Steve Jobs por nada". O interessante é que, apesar de reconhecer que Jobs era severo, Guy diz que não trocaria o seu trabalho por nada. Isso é mais uma evidência da força da missão que Steve pregava em seus dominados. Além disso, é a evidência da típica dominação carismática, aquela que vem de dentro para fora, fazendo com que a crença dos dominados os impulsione a seguir a missão do líder.

Um outro ex-funcionário relata o trato severo de Jobs e a inculcação da preocupação com a extinção das falhas:

When Steve was pissed off about something, it got fixed at a pace I've never seen then or since in my professional life. I guess some people reacted that fast out of fear, but more directly, you would get used to refusing to accept anything but flawless execution.

Ainda na década de 80, Steve Jobs explica a sua fixação pela excelência, o que reforça ainda mais o apego a esse ponto de vista como sua missão:

We have an environment where excellence is really expected. What's really great is to be open when [the work] is not great. My best contribution is not settling for anything but really good stuff, in all the details. That's my job - to make sure everything is great.

John Ive, o grande responsável pelo design dos produtos da Apple junto com Steve, fala sobre a preocupação do CEO com a excelência:

1 Citação feita em português em artigo da mídia. 
It cost him most. He cared the most. He worried the most deeply. He constantly questioned: is this good enough? Is this right? And despite all his successes, all his achievements, he never presumed, he never assumed that we would get there in the end. And when the prototypes failed, it was with great intent, with faith, he decided to believe we would eventually make something great. [...] So his I think was a victory for beauty for purity, and as he would say, for giving a damn.

Em um discurso para a Universidade de Stanford em 2005, Jobs fala do seu apego ao trabalho como algo que ele dizia amar. Ele fala para uma plateia de estudantes que estão à procura de um emprego que lhes satisfaçam. O discurso de Steve funciona nesse contexto, o que mostra sua grande capacidade de falar de si mesmo de maneira culturalmente compatível com o ambiente em que está. Apesar de este não ser uma prática dentro da sua empresa, o trecho mostra como ele sabe se posicionar diante dos outros de modo a induzi-los a acreditar em sua crença, de maneira semelhante a como a dominação carismática age. Isso remete ao poder de persuasão carismática além da associação a um significado revolucionário, transformador, capaz de transcendência (WEBER, 1994) e à boa leitura cultural do contexto em que está inserido (BOWDEN, 20I0; FILHO; COSTA, 2006; HOUSE , 1999). O trecho mostra não só seu poder de articulação, mas como ele cria um discurso interessante para sua missão dentro da empresa, ampliando seu significado e criando uma filosofia de vida:

\footnotetext{
You've got to find what you love. And that is as true for your work as it is for your lovers. Your work is going to fill a large part of your life, and the only way to be truly satisfied is to do what you believe is great work. And the only way to do great work is to love what you do. If you haven't found it yet, keep looking. Don't settle. As with all matters of the heart, you'll know when you find it. And, like any great relationship, it just gets better and better as the years roll on. So keep looking. Don't settle.
}

Apesar do seu poder persuasivo e das evidências de seu poder sobrenatural, Jobs também recebeu críticas desses liderados, como evidencia o trecho de um ex-funcionário que relatou diretamente na internet sua experiência com Jobs na Apple:

For a company that claims to enhance people's lives through technology - they know nothing about life. Nothing at all. I'm disheartened as I loved Apple. I loved their products and I've been an advocate for what they allegedly stand for. Unfortunately I've seen behind their glossy and polished stainless steel exterior, I've walked through their frosted glass doors and seen a toxic culture of manipulation, intimidation, threats and politics that are so incongruent to the values they preach.

O ex-funcionário fala de uma cultura nociva e incongruente com a maneira paradisíaca que descrevem a empresa. Entretanto isto não é suficiente para dizer que o carisma de Jobs estava se extinguindo já que a literatura prevê que há casos de dominados que não se deixam levar pelo líder carismático. Tal constatação aponta para crises na dominação (BEYER, 1999), indivíduos que não se deixam envolver pela retórica do líder carismático (BRYMAN, I993) e para a situação em que alguns enxergar a liderança carismática como negativa (DITOMASO, I993). Mais curioso ainda é ver comentários que constatam uma certa decadência da vida pessoal dos empregados, mas nem por isso condenam o que acontece na Apple. Um headhunter que trabalhou para Jobs relata o seguinte: "People join and stay because they believe in the mission of the company, even if they aren't personally happy". 
Mark Kawano, ex-funcionário que trabalhou 7 anos na Apple, parece falar com satisfação sobre a severa rotina da empresa. Ele relata que alguns se apaixonam pelo trabalho com Jobs e sua missão que prega a qualidade. Ele argumenta que as pessoas que reclamam são apenas aqueles que não conseguiram ver o valor do esforço que empreenderam:

The reality is, the people who thrived at Apple were the people who welcomed that desire and passion to learn from working with Steve, and just really were dedicated to the customer and the product. They were willing to give up their weekends and vacation time. And a lot of the people who complained that it wasn't fair... they didn't see the value of giving all that up versus trying to create the best product for the customer and then sacrificing everything personally to get there.

O engenheiro Steve Wozniak, que acompanha Jobs desde a fundação da empresa, comenta o tratamento agressivo do CEO:

\begin{abstract}
He would directly confront people and almost call them idiots. But you know what? When they confronted him back and told him why they were right in understandable forms, he was just testing and learning... and he would respect those people and give them high privileges in the company... That was one thing he did respect-someone who believed enough in their own ideas to speak for him, not just shut up and be shy around him.
\end{abstract}

A visão de Wozniak do tratamento de Jobs evidencia o poder da liderança carismática. Ele não entende a rigidez do CEO como algo prejudicial, mas sim como algo benéfico para a empresa. O poder da missão, da busca pela excelência, aparece como algo interno ao engenheiro, algo em que ele acredita como se fosse o próprio líder, o que revela a interiorização da missão e dos valores desse líder. Conforme mencionado, que o poder do carisma incide de dentro para fora (WEBER, 1994). Essa transformação de dentro para fora fica mais clara com a declaração de Chuq Von Rospach, que dedica a construção de si mesmo à influência de Steve Jobs:

I am who I am today because of Steve, through the companies and the products and the technologies he fostered; more importantly, because of the people he brought in and mentored who turned into people that mentored me. Because of the thinking and attitudes he promoted and inoculated that became key parts of what I've become. I'm the person I am because of Steve and what he did, the opportunities he created, and the attitudes and expectations he baked into those around him.

Steve, como líder carismático, deixa claro que sua busca não é econômica, mas por algo que vai além disso, o que remete ao afirmado por Weber (1994). O trecho atribuído a Steve mostra sua rejeição à recompensa econômica como propulsora de suas ações quando uma outra pessoa (Sculley) tenta fazer afirmações contrárias a tal posicionamento:

My passion has been to build an enduring company where people were motivated to make great products. The products, not the profits, were the motivation. Sculley flipped these priorities to where the goal was to make money. It's a subtle difference, but it ends up meaning everything. 
Outro ponto que a literatura deixa claro é a possível perda de carisma e a transformação do poder, que acontece conforme previsto por Weber (I994), Conger (I993), Calás (I993) e Breuilly (20II). O câncer que acometeu Jobs e sua consequente morte deixam claro que ele e sua empresa tinham ciência disso. O analista industrial da Apple diz que a visão de Steve foi transportada para os executivos da empresa: "has a deep bench of executives who know how Steve Jobs thinks, what his vision is for the next decade and are more than capable". A visão inclui não só as ordens operacionais, mas também a cultura da empresa carregará o modo de dominação iniciado por Jobs. O próprio CEO afirma que são os valores da empresa que a regem: "Apple is driven by 'core values'. We have the same values now, as we had then. We're a little more experienced, certainly beat-up, but the core values are the same". Os valores de que Jobs menciona se referem a um certo modo de funcionar da Apple que foi fundado por ele. No caso, os valores que ele pregou se alastram pela empresa e são esses valores que vão perpetuar a sua presença, dominação carismática que exerceu. Como previsto na literatura, o carisma pode passar para um determinado grupo e até para instituições, o que parece ser o caso da Apple.

Três anos após a morte de Steve Jobs, Tim Cook, seu sucessor como CEO, escreveu um email para todos os funcionários da empresa. Nele, Tim fala do legado de Jobs e dos valores que ele criou:

Team, Sunday will mark the third anniversary of Steve's passing. I'm sure that many of you will be thinking of him on that day, as I know I will. I hope you'll take a moment to appreciate the many ways Steve made our world better. Children learn in new ways thanks to the products he dreamed up. The most creative people on earth use them to compose symphonies and pop songs, and write everything from novels to poetry to text messages. Steve's life's work produced the canvas on which artists now create masterpieces. Steve's vision extended far beyond the years he was alive, and the values on which he built Apple will always be with us. Many of the ideas and projects we're working on today got started after he died, but his influence on them - and on all of us - is unmistakeable. Enjoy your weekend, and thanks for helping carry Steve's legacy into the future.

A lembrança da Apple, seu legado e seus valores atuam como uma espécie de memória coletiva daquilo que Steve fundou e precisa ainda existir para que a dominação carismática da instituição persista. Tim se mostra como porta-voz, uma espécie de sucessor que pode pregar a mesma mensagem carismática de Jobs e, assim, reforçar os valores que fundamentam a organização.

\section{Conclusão}

A pesquisa analisou o papel de Steve Jobs na empresa que fundou, a Apple, segundo a ótica da teoria da dominação de Max Weber. Foi possível entender a trajetória do empreendedor com fortes traços de liderança carismática. Desde suas habilidades tidas como extraordinárias até seu apego à missão de transformar a experiência com computadores.

Concluímos, então, que a trajetória de Steve Jobs tem forte apelo carismático. Através de relatos de quem trabalhou com ele e das suas próprias falas e realizações, foi possível encontrar diversas relações com o funcionamento do poder carismático em termos weberianos puros e 
daqueles que o atualizaram. Uma das consequências de tal entendimento é perceber o potencial de impacto de uma liderança carismática, podendo criar não só liderados para se completar uma missão, mas também conquistar a admiração e formar seguidores. Também é possível compreender que a literatura na área ganha força, pois é possível encontrar fortes relações entre ela e a realidade de Jobs como líder carismático. Destaca-se ainda a riqueza de entendimento sobre a função da liderança carismática com as descrições e inferências feitas a partir dos dados e da teoria.

É de se imaginar que existam outras formas de dominação relacionadas ao fenômeno da liderança carismática. Jobs foi o CEO de sua empresa por muito tempo, o que dá a ele o status do cargo e uma influência da estrutura organizacional sobre seus liderados. Também é possível mencionar uma certa força da tradição de sua vida na empresa nessa dominação pela sua longa trajetória na empresa. Apesar disso, a força do carisma não é excluída. Conforme indica Alves (2003), essas formas de dominação podem se mesclar e formar estruturas híbridas.

Uma das limitações do estudo é a fonte de dados. Os dados secundários em escassez podem ter limitado os achados e impossibilitado a análise de uma maneira mais profunda. Vale destacar que as informações disponíveis sobre a empresa são escassas provavelmente devido ao interesse em preservar segredos da empresa. Futuras pesquisas podem se utilizar de dados mais próximos da realidade organizacional, como entrevistas diretas com os próprios funcionários ou ex-funcionários para analisar com mais propriedade a liderança desenvolvida por Jobs, podendo expandir a análise para o hibridismo com outros poderes weberianos, como mencionado anteriormente.

\section{Referências}

ALVES, S. Racionalidade, carisma e tradição: nas organizações empresariais contemporâneas. Universitária UFPE, 2003.

BAUER, M. W.; AARTS, B. A Construção do Corpus: Um Princípio para a Coleta de Dados Qualitativos in Pesquisa Qualitativa com Texto, Imagem e Som: um manual prático. Martin W. Bauer, George Gaskell (orgs), v. IO, 2010.

BEYER, J. Two approaches to studying charismatic leadership: Competing or complementary? The Leadership Quarterly, v. IO, n. 4, p. 575-588, 2000.

BOWDEN, G. Obama, Palin, and Weber: Charisma and social change in the 2008 US Election. Canadian Review of Sociology/Revue canadienne de sociologie, v. 47, n. 2, p. I7I-I90, 20 IO.

BREUILLY, J. Max Weber, charisma and nationalist leadership. Nations and nationalism, v. I7, n. 3, p. 477-499, 201 I.

BRYMAN, A. Charismatic leadership in business organizations: Some neglected issues. The Leadership Quarterly, v. 4, n. 3, p. 289-304, 1993. 
CALÁS, M. Deconstructing charismatic leadership: Re-reading Weber from the darker side. The Leadership Quarterly, v. 4, n. 3, p. 305-328, 1993.

CONGER, J. Max Weber's conceptualization of charismatic authority: Its influence on organizational research. The Leadership Quarterly, v. 4, n. 3, p. 277-288, 1993.

CRESWELL, J. Projeto de pesquisa: métodos qualitativo, quantitativo e misto. Porto Alegre: Artmed, 20IO.

LIMA FILHO, D., DA COSTA, M. Lula e a blindagem arquetípica: Como a retórica supera o contrato eleitoral. por João Carlos Correia, p. 197.

DITOMASO, N. Weber's social history and Etzioni's structural theory of charisma in organizations: Implications for thinking about charismatic leadership. The Leadership Quarterly, v. 4, n. 3, p. 257-275, I993.

SANTOS, L. Um mapeamento das aproximações entre Weber e Nietzsche. Plural (São Paulo. Online), v. 2I, n. I, p. I39-I56', 2014.

FLICK, U. Uma introdução à pesquisa qualitativa. Porto Alegre: Bookman, 2004.

GIFFORD, J. Grandes líderes da história. São Paulo: Senac, 20II.

HOUSE, R. Weber and the neo-charismatic leadership paradigm: A response to Beyer. The Leadership Quarterly, v. Io, n. 4, p. 563-574, 2000.

ISAACSON, W. Steve Jobs. São Paulo: Companhia das Letras, 20II.

JERMIER, J. Introduction-charismatic leadership: Neo-weberian perspectives. The Leadership Quarterly, v. 4, n. 3, p. 217-233, 1993.

KLEIN, K.; HOUSE, R. On fire: Charismatic leadership and levels of analysis. The Leadership Quarterly, v. 6, n. 2, p. I83-I98, I995.

LADKIN, D. The enchantment of the charismatic leader: Charisma reconsidered as aesthetic encounter. Leadership, v. 2, n. 2, p. I65-I79, 2006.

MERRIAM, S. Qualitative research in practice: Examples for discussion and analysis. JosseyBass Inc Pub, 2002.

RAMOS, G. A sociologia de Max Weber (Sua importância para a teoria e a prática da Administração). Revista do Serviço Público, Brasília, v. 3, n. 2, p. 267-282, ago/set, 2000.

ROSELINO, L. A dialética entre carisma e racionalidade no pensamento de Max Weber. In:, 4, 20IO. Anais: UFSCar, 2010. 
SHARMA, A.; GRANT, David. Narrative, drama and charismatic leadership: The case of Apple's Steve Jobs. Leadership, v. 7, n. I, p. 3-26, 20 II.

WEBER, M. Economia e sociedade: fundamentos da sociologia compreensiva. Editora Universidade de Brasília., I994.

YUKI, G. An evaluation of conceptual weaknesses in transformational and charismatic leadership theories. The leadership quarterly, v. IO, n. 2, p. 285-305, I999. 